PONTIFÍCIA UNIVERSIDADE CATÓLICA DO RIO DE JANEIRO

\title{
A percepção do consumidor em relação ao uso consciente de água
}

Gabriel Monlevad

Trabalho de Conclusão de Curso

Centro de CIÊnCIAS SOCIAIS - CCS

DePARTAMENTO de AdMINISTRAÇÃo

Graduação em Administração de Empresas 
Gabriel Monlevad

A percepção do consumidor em relação ao uso consciente de água

Trabalho de Conclusão de Curso

Trabalho de Conclusão de Curso, apresentado ao programa de graduação em Administração da PUC-Rio como requisito parcial para a obtenção do título de graduação em Administração.

Orientadora: Marina Frid

Rio de Janeiro, junho de 2018. 


\section{Resumo}

Monlevad, Gabriel. A percepção do consumidor em relação ao uso consciente de água. Rio de Janeiro, 2018. 34 p. Trabalho de Conclusão de Curso - Departamento de Administração. Pontifícia Universidade Católica do Rio de Janeiro.

Este trabalho pretende analisar o comportamento do consumidor em relação a campanhas de uso consciente de água, afim de verificar suas percepções, motivações e atitudes que influenciam o processo de decisão para escolha destas empresas. Além de averiguar o impacto destas ações na conscientização ambiental e imagem da marca.

\section{Palavras-chave}

Comportamento do consumidor. Percepção. Sustentabilidade. Água.

\section{Abstract}

Monlevad, Gabriel. The perception of the consumer regarding the conscious use of water. Rio de Janeiro, 2018. 34 p. Paper of Conclusion of Course - Department of Administration. Pontifical University Catholic of Rio De Janeiro.

This paper intends to analyze the behavior of the consumer in relation to campaigns of conscious use of water, to verify their perceptions, motivations and attitudes that influence the decision process to choose these companies. In addition to investigating the impact of these actions on environmental awareness and brand image.

Keywords

Consumer behavior. Perception. Sustainability. Water. 


\section{Sumário}

1 O tema e o problema de estudo 6

1.1. Introdução ao tema e ao problema do estudo 6

1.2. Objetivos do estudo 11

1.3. Delimitação e foco do estudo 11

1.4. Justificativa e relevância do estudo 12

2 Referencial teórico 13

2.1. Comportamento do Consumidor 13

2.1.1. Fatores psicológicos como motivação de compra 14

2.1.2. Atitude e Intenção de Compra 15

2.2. Consumo Sustentável 16

$\begin{array}{lr}\text { 2.3. Marketing Verde } & 18\end{array}$

3 Métodos e procedimentos de coleta e de análise de dados 19

3.1. Etapas de coleta de dados 19

3.2. Perfil dos entrevistados 20

3.3. Forma de tratamento e análise de dados 21

4 Apresentação e análise dos resultados 22

5 Conclusões $\quad 28$

6 Referências Bibliográficas $\quad 29$

$\begin{array}{ll}\text { Anexo } 1 \text { Entrevista } & 32\end{array}$ 


\section{Lista de figuras}

Figura 1 Água no Brasil, Fonte: Folha de São Paulo, 2015............................................ 7

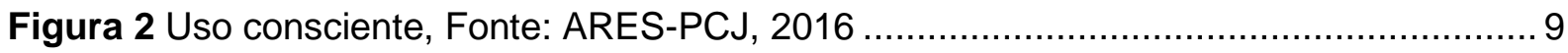

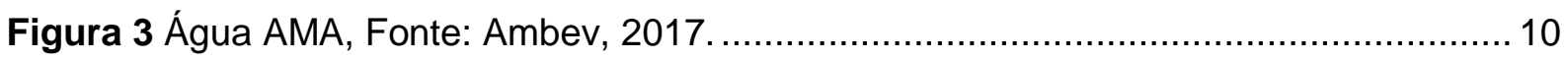

Figura 4 Modelo do comportamento do consumidor, Fonte: Kotler e Keller ,2006.............. 13

Figura 5 Pirâmide das necessidades de Maslow, Fonte: Brasil Escola, 2006. ................... 15

Figura 6 Abordagens do consumo verde e do sustentável, Fonte: Gonçalvez-Dias e Moura,

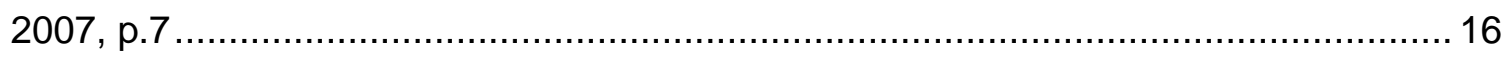

Figura 7 Consumo sustentável, Fonte: Portal Brasil, 2015............................................. 17

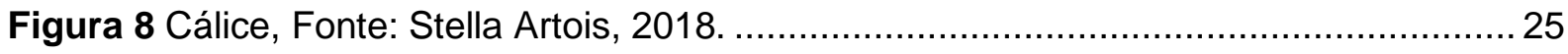

\section{Lista de Tabelas}

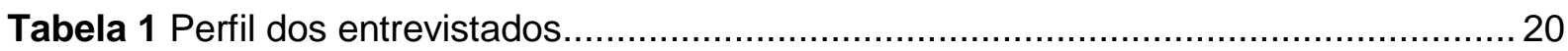




\section{O tema e o problema de estudo}

\subsection{Introdução ao tema e ao problema do estudo}

Até o ano de 2050 é previsto um aumento da necessidade de recursos hídricos mundial de 55\%, segundo Relatório Mundial das Nações Unidas sobre Desenvolvimento dos Recursos Hídricos de 2015. Isto é consequência principal de uma demanda crescente do setor industrial, geração de energia, agricultura e consumo doméstico, acompanhando o crescimento populacional, afetando o desenvolvimento sustentável dos respectivos setores, assim como a alocação deste recurso tão importante para a saúde do planeta, que também impacta significativamente nas economias locais e no bem-estar da população.

O Rio de Janeiro é o estado brasileiro que possui o maior índice de consumo per capita de água no país, de acordo com dados do SNIS (Sistema Nacional de Informações sobre Saneamento) publicado em 2015. Segundo o mesmo órgão, no ano de 2013, seus habitantes consumiram cerca de 250 litros de água por dia, mais que o dobro de vezes recomendado pela ONU (Organização das Nações Unidas), que considera suficientes 110 litros por pessoa e muito maior que a média nacional de 163 litros.

A diferença do consumo entre o Rio e os outros estados é nítida. Entre outros fatores prováveis para esse quadro estão os baixos índices de medição na distribuição, levando parte dos dados a serem estimados. $O$ índice de medição das ligações de água, que considera o volume de água levado para residências por meio da medição do hidrômetro, é de $65 \%$, enquanto a média do país é de $91 \%$. Desta forma este consumo muito elevado e falta eficiência na distribuição compõem uma formula desastrosa para o país e principalmente para o estado, contribuindo ainda mais para uma perspectiva negativa do futuro. Agravando ainda mais o cenário, muito do que é produzido de água potável se desperdiça, se perde durante o trajeto até o destino e, por isso, não é possível nem mesmo quantificado de maneira precisa essas perdas, conforme demonstra a Figura 1 abaixo 

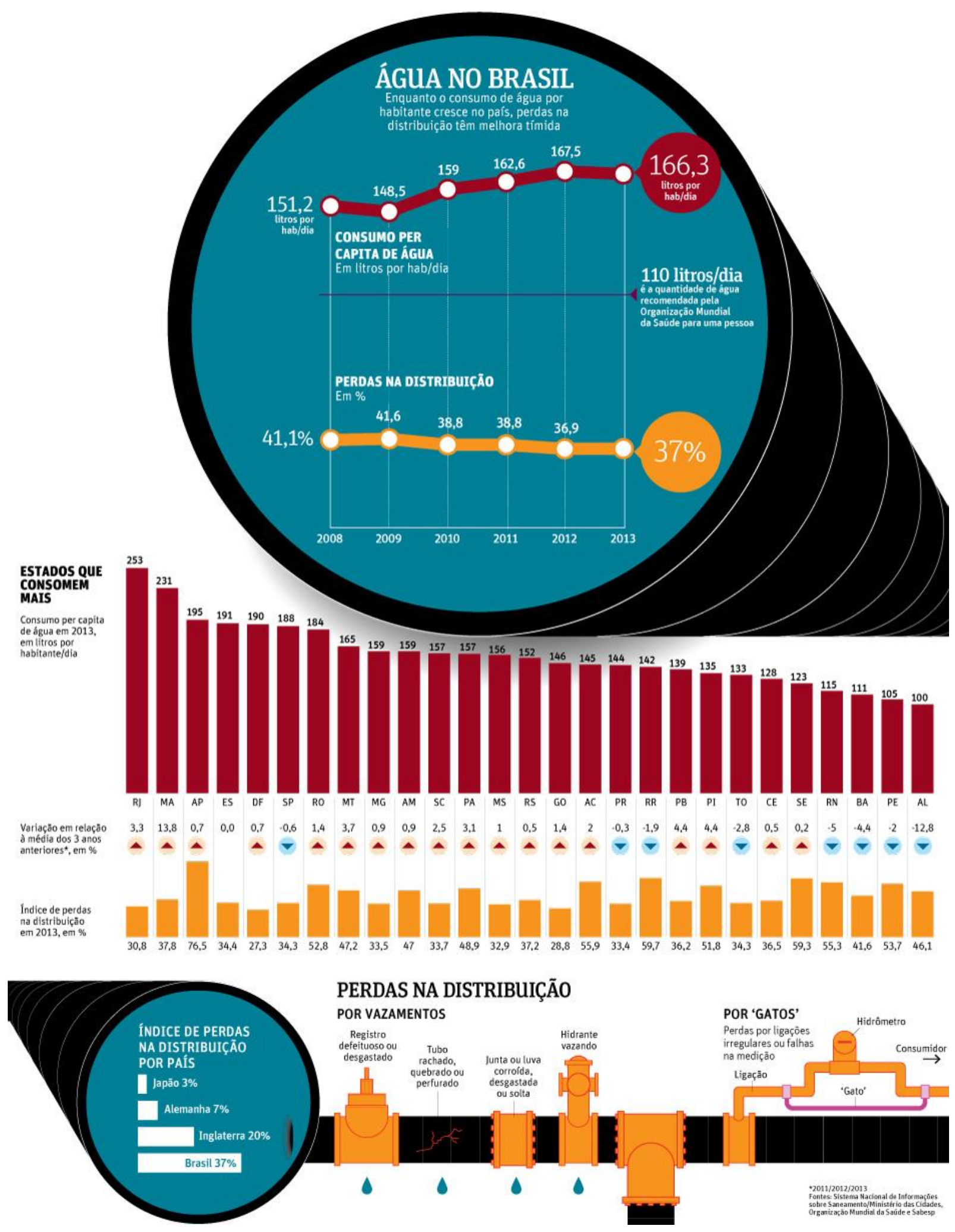

Figura 1 Água no Brasil, Fonte: Folha de São Paulo, 2015. 
Com o objetivo de conscientizar a população mundial sobre o uso consciente da água e buscando a melhoria nos processos de medição e distribuição, em 1992 a ONU instituiu o "Dia Mundial da Água", publicando o documento "Declaração Universal dos Direitos da Água" onde foram relacionados dez tópicos para reflexão, que merecem ser citados a fim de contextualizar a importância deste recurso natural:

1 - A água faz parte do patrimônio do planeta. Cada continente, cada povo, cada nação, cada região, cada cidade, cada cidadão, é plenamente responsável aos olhos de todos.

2 - A água é a seiva de nosso planeta. Ela é condição essencial de vida de todo vegetal, animal ou ser humano. Sem ela não poderíamos conceber como são a atmosfera, o clima, a vegetação, a cultura ou a agricultura.

3 - Os recursos naturais de transformação da água em água potável são lentos, frágeis e muito limitados. Assim sendo, a água deve ser manipulada com racionalidade, precaução e parcimônia.

4 - O equilíbrio e o futuro de nosso planeta dependem da preservação da água e de seus ciclos. Estes devem permanecer intactos e funcionando normalmente para garantir a continuidade da vida sobre a Terra. Este equilíbrio depende em particular, da preservação dos mares e oceanos, por onde os ciclos começam.

5 - A água não é somente herança de nossos predecessores; ela é, sobretudo, um empréstimo aos nossos sucessores. Sua proteção constitui uma necessidade vital, assim como a obrigação moral do homem para com as gerações presentes e futuras.

6 - A água não é uma doação gratuita da natureza; ela tem um valor econômico: precisase saber que ela é, algumas vezes, rara e dispendiosa e que pode muito bem escassear em qualquer região do mundo.

7 - A água não deve ser desperdiçada, nem poluída, nem envenenada. De maneira geral, sua utilização deve ser feita com consciência e discernimento para que não se chegue a uma situação de esgotamento ou de deterioração da qualidade das reservas atualmente disponíveis.

8 - A utilização da água implica em respeito à lei. Sua proteção constitui uma obrigação jurídica para todo homem ou grupo social que a utiliza. Esta questão não deve ser ignorada nem pelo homem nem pelo Estado. 
9 - A gestão da água impõe um equilíbrio entre os imperativos de sua proteção e as necessidades de ordem econômica, sanitária e social.

10 - O planejamento da gestão da água deve levar em conta a solidariedade e o consenso em razão de sua distribuição desigual sobre a Terra.

Através destes tópicos relacionados acima, pode-se perceber que embora a população tenha conhecimento da importância da água para a manutenção da vida e do equilíbrio do planeta, ainda há muita negligência com o consumo de água potável no mundo, uma vez que o seu uso vem aumentando proporcionalmente ao crescimento da população. Se este desequilíbrio entre demanda e oferta for mantido, muito provavelmente será enfrentado um déficit global de recursos naturais cada vez mais grave.

Diante da escassez deste recurso tão essencial para a vida, o comportamento ecologicamente consciente pode ser um grande aliado na busca do consumo cada vez mais racional. Campanhas promovidas por grandes empresas alertando os problemas enfrentados pelo uso desenfreado é uma maneira de mostrar à população como contribuir para a melhor utilização dos recursos hídricos e devem ser cada vez mais propagados. A Figura 2 abaixo exemplifica uma dessas campanhas.

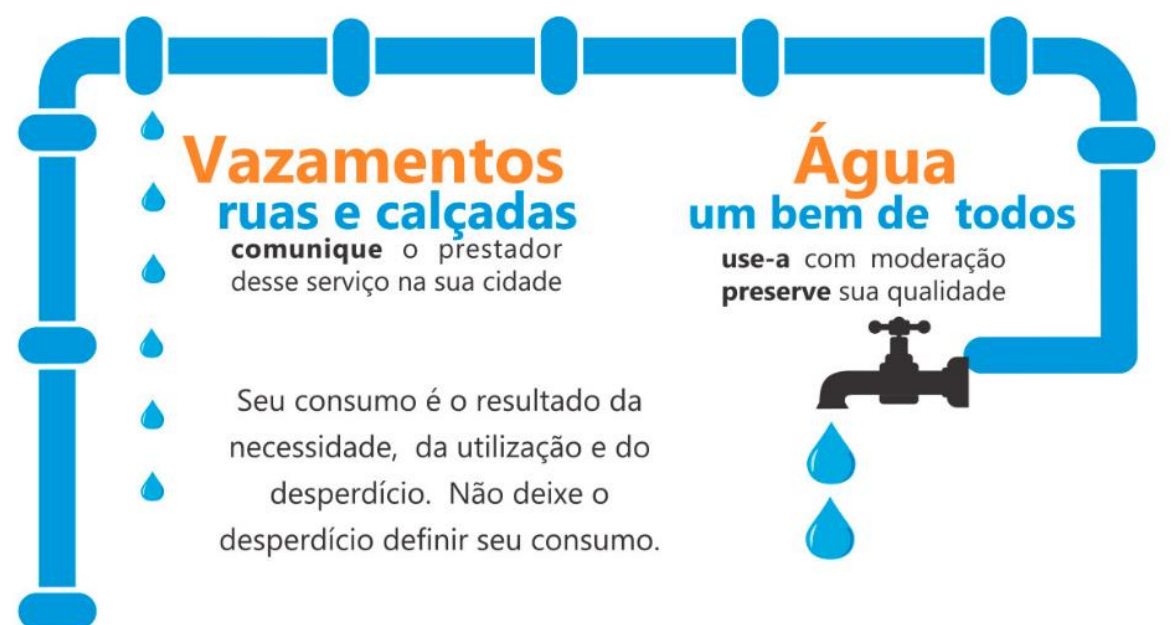

Seja consciente, use de forma racional

Figura 2 Uso consciente, Fonte: ARES-PCJ, 2016 
Esta campanha ilustra perfeitamente a necessidade do consumo consciente e pertence à Agência Reguladora dos Serviços de Saneamento das Bacias dos Rios Piracicaba, Capivari e Jundiaí (ARES-PCJ). A figura faz parte de um folder sobre sustentabilidade disponibilizado como material de divulgação institucional da agência.

Outro exemplo interessante foi iniciado no primeiro semestre de 2017, quando a Ambev lançou sua primeira marca de água mineral, a AMA conforme mostra a Figura 3. Sem fins lucrativos, todo o lucro com a venda de garrafas é revertido a projetos que disponibilizam água potável para as regiões semiáridas do Brasil. O processo é auditado pela KPMG, confirmando a sua seriedade. Além dos $\mathrm{R} \$ 939.662,00$ investidos até junho de 2018 , mais de 6.500 pessoas já foram beneficiadas pelo projeto. A empresa apoia nove locais através da construção de poço profundo para levar água encanada às residências utilizando placas solares ou sistema fotovoltaico para reduzir custos com energia para a distribuição da água. Também recuperam e readequam as redes de distribuição já existentes, juntamente com a instalação de hidrômetros.

\section{CHEGOU AMA,}
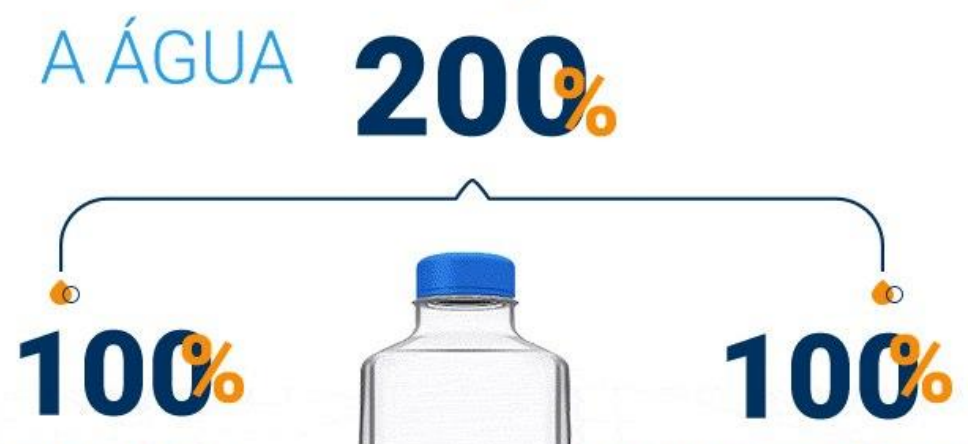

DE HIDRATAÇÃO PARA QUEM BEBE



Figura 3 Água AMA, Fonte: Ambev, 2017. 
Tendo em vista as informações apresentadas acima sobre a problemática dos recursos hídricos no Brasil, este trabalho procura investigar a seguinte questão: qual é a percepção do consumidor com relação às empresas que realizam campanhas de consumo consciente de água?

\subsection{Objetivos do estudo}

Este trabalho tem como objetivo prioritário identificar qual a importância que o consumidor atribui às empresas que realizam campanhas de consumo consciente de água e se esse tipo de abordagem é capaz de modificar a preocupação da população sobre esse assunto.

Entre outros objetivos do estudo também estão: 1) identificar empresas, atuantes no mercado brasileiro, que possuem benchmarking ${ }^{1}$ em implementação de Marketing Verde com o foco no consumo consciente de água e analisar suas campanhas publicitárias para divulgação destas boas práticas; 2) relacionar os principais fatores que levam os consumidores a comprar produtos com consciência ambiental e sustentabilidade, a fim de traçar o perfil destas pessoas para uma análise futura que possa complementar este estudo; 3) levantar conceitos teóricos sobre as empresas destacadas e sua relação com consumidores ecologicamente conscientes.

\subsection{Delimitação e foco do estudo}

Este estudo é voltado mais especificamente para abordar a questão do benchmarking de conscientização a respeito do consumo de água de empresas atuantes no mercado nacional, sob a ótica do comportamento do consumidor. Tal perspectiva de análise se mostra interessante e relevante pois abre precedente para intensificação de boas práticas organizacionais, visando a Responsabilidade Social de diversas empresas diante do consumo de recursos hídricos.

\footnotetext{
1 Benchmarking: É o processo de avaliação da empresa em relação à concorrência, por meio do qual incorpora os melhores desempenhos de outras firmas e/ou aperfeiçoa os seus próprios métodos.
} 
Pretende-se analisar o grau de importância que o consumidor confere às empresas que contribuem para o uso consciente da água e que também auxiliam na sua distribuição e facilitam o seu acesso à lugares que ainda não possuem. Não será medido retorno financeiro destas campanhas, custos internos ou resultados operacionais, somente a percepção do consumidor. $O$ estudo foi realizado na cidade do Rio de Janeiro durante a primeira semana do mês de março do ano de 2018.

\subsection{Justificativa e relevância do estudo}

Este estudo é relevante para o meio acadêmico pois levanta questões pouco abordadas no tema Marketing Verde e consumo sustentável. Também é importante sob a ótica comercial, pois o impacto sobre os consumidores é chave na pesquisa, a ponto de determinar suas escolhas em relação a produtos que possuem a sustentabilidade com uso de água como diferencial competitivo.

Além dos motivos citados acima, o assunto ajuda organizações que já possuem estas campanhas, pois é uma forma de reforçar positivamente o valor sustentável, abrindo precedente para novas ações. 


\section{Referencial teórico}

\subsection{Comportamento do Consumidor}

Segundo Solomon (2011, p.33), o comportamento do consumidor "é o estudo dos processos envolvidos quando indivíduos ou grupos selecionam, compram, usam ou descartam produtos, serviços, ideias ou experiências para satisfazer necessidades e desejos". De acordo com Richers (1984), a maneira como o consumidor se comporta pode ser influenciada pelas atividades mentais e emocionais realizadas durante o processo de escolha, aquisição e utilização de produtos e/ou serviços. Estas atividades estão diretamente ligadas à satisfação das necessidades e desejos das pessoas.

Já para Kotler e Keller (2006), um dos principais fatores que o marketing busca atingir é satisfazer as vontades do consumidor e para obter sucesso é necessário conhecer o seu comportamento em relação às compras. A Figura 4 apresenta o modelo proposto pelos autores de estímulos e respostas que atuam na compra, o ambiente a qual o indivíduo está inserido e as influências a qual ele está submetido tem grande impacto no consciente do consumidor.

\section{Modelo do comportamento do consumidor}

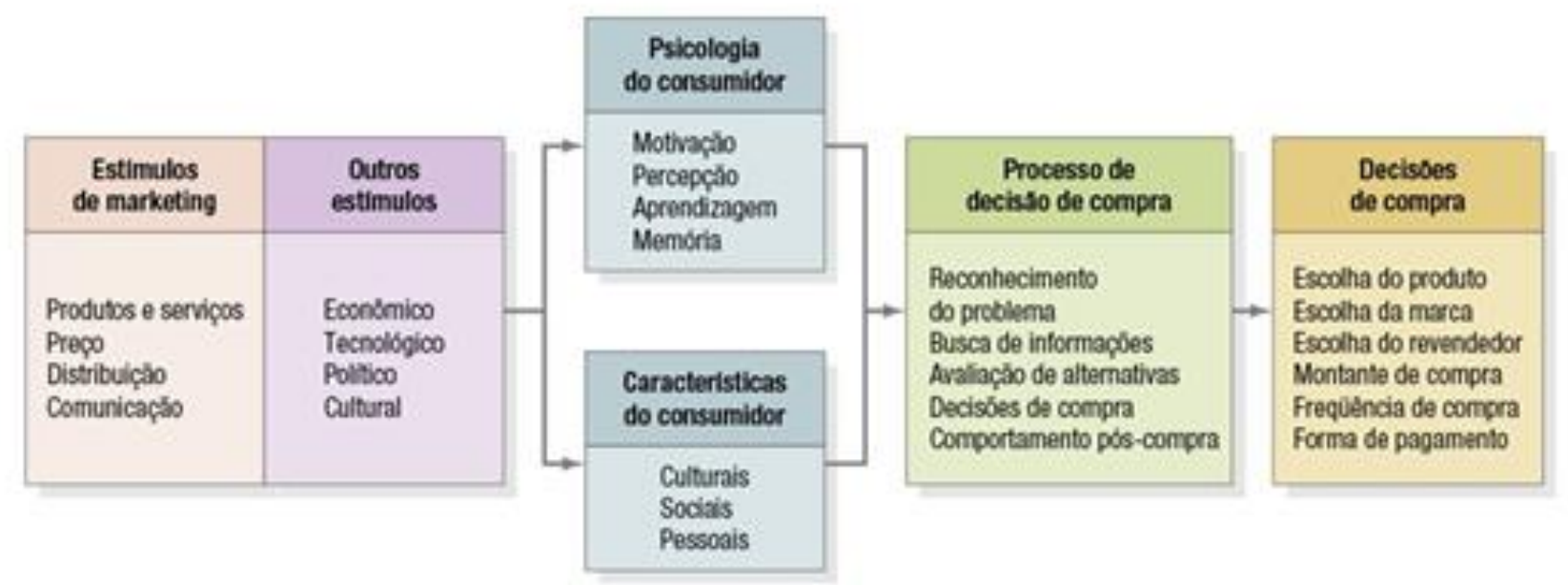

Figura 4 Modelo do comportamento do consumidor, Fonte: Kotler e Keller ,2006 


\subsubsection{Fatores psicológicos como motivação de compra}

Segundo Sant'Anna (1989), é necessário que a mente do consumidor desenvolva alguns estados para que a decisão de compra seja tomada, são eles: haver uma necessidade, ter consciência dessa necessidade, conhecer o objeto que a poderá sanar, querer satisfazêla e tomar a decisão por um produto específico. "Uma necessidade passa a ser um motivo quando alcança determinado nível de intensidade. Um motivo é uma necessidade que é suficientemente importante para levar a pessoa a agir" (Kotler e Keller, 2006, p. 183). Portanto, identificar as motivações e entender como funcionam é importante. De acordo com o livro Administração de Marketing, de Kotler e Keller (2006, p. 183-184), há três teorias capazes de explicar a motivação:

a) Teoria de Freud: apontou as forças psicológicas presentes no comportamento pessoal como inconscientes e que o próprio indivíduo não é capaz de compreender todas as suas motivações. Dessa maneira, a forma, o material, a cor, o tamanho e o nome são fatores que influenciam na decisão de compra. A aparência, segundo essa teoria, é crucial para estimular as emoções e associações que levam a necessidade a se tornar uma motivação.

b) Teoria de Maslow: busca explicar porque as pessoas são motivadas por necessidades específicas em alguns momentos de suas vidas. Abraham Maslow identificou que há uma hierarquização das necessidades dos indivíduos, das mais urgentes para as menos urgentes e construiu a "Pirâmide de Maslow" ilustrada na Figura 5, ela distribui-se da base para o topo em grau de importância da seguinte forma: necessidades fisiológicas, necessidades de segurança, necessidades sociais, necessidades de estima e necessidades de autorrealização. Essa teoria explica como os produtos se adequam nos planos, objetivos e vida dos consumidores. 


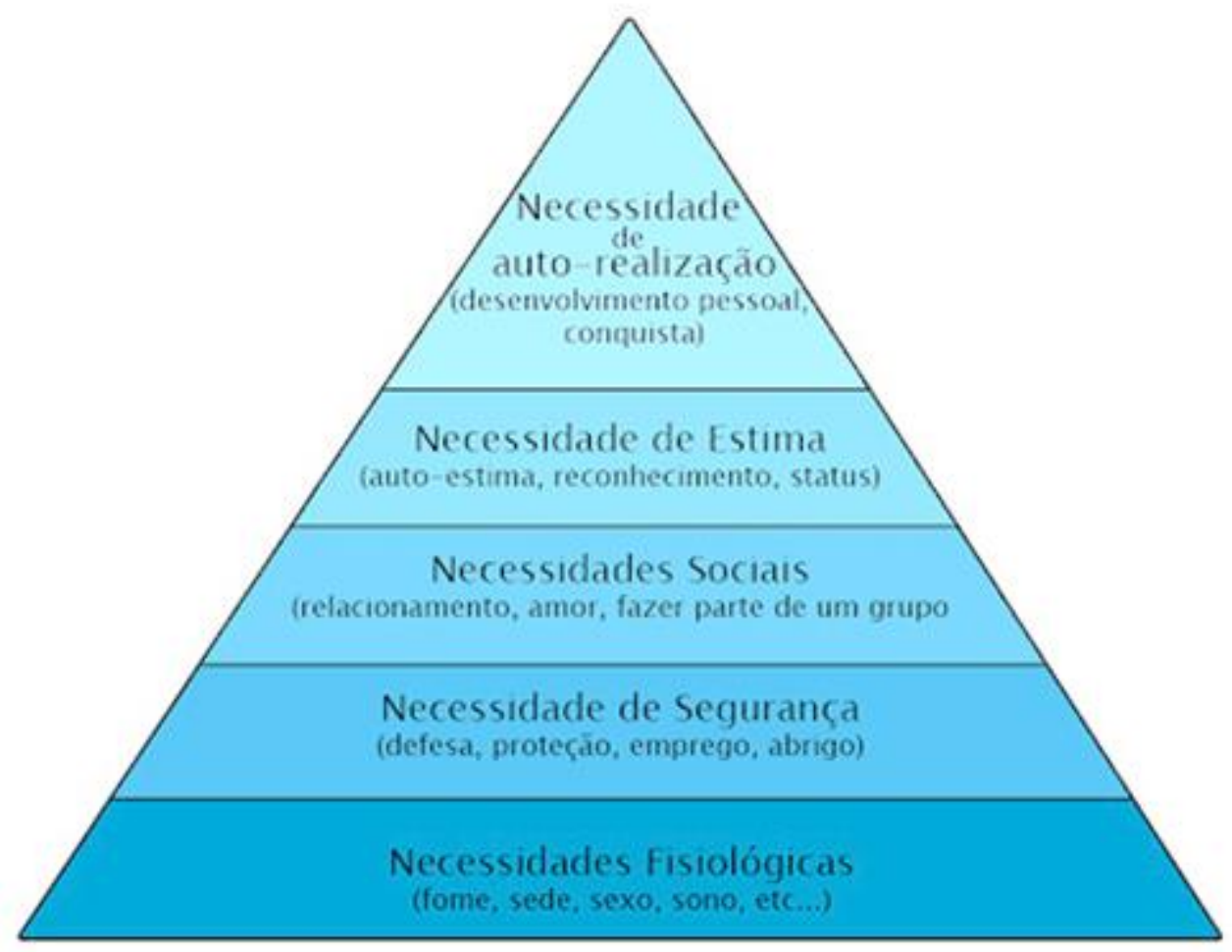

Figura 7 Pirâmide das necessidades de Maslow, Fonte: Brasil Escola, 2006.

c) Teoria de Herzberg: divide a análise em fatores que causam insatisfação e fatores que causam satisfação. Defende que a compra só é motivada se os fatores satisfatórios estiverem expostos de maneira clara, só a ausência de fatores de insatisfação não é suficiente. Os pontos satisfatórios têm grande importância sobre a marca que o consumidor irá escolher.

\subsubsection{Atitude e Intenção de Compra}

A atitude de compra se define como, "uma avaliação duradoura e geral das pessoas, objetos, propagandas ou questões. Qualquer coisa em relação à qual se tem uma atitude é chamado de objeto de atitude." (Solomon, 2011). Conforme a hierarquia de valores que compõe a avaliação dos consumidores a respeito da atitude para compra dos produtos, provenientes destas campanhas, acredita-se que os pesquisados terão a criação sistêmica das crenças e atitudes favoráveis aos valores para a consciência ecológica e consequentemente a avaliação positiva em relação a práticas sustentáveis. 


\subsection{Consumo Sustentável}

Segundo Ana Milhen (2014) do Instituto Akatu, "consumir de forma consciente é levar em consideração os impactos ambientais e sociais da produção, uso e descarte de produtos e serviços". Diante disto, para o consumidor escolher um produto, serviço ou até mesmo nos seus hábitos rotineiros, é necessário considerar qual o impacto de produção e descarte, assim sendo este pensamento é diretamente ligado a importância da menor influência negativa dos hábitos de consumo com meio ambiente, para a melhor utilização dos recursos naturais, como a água. Estes fatores estão descriminados no quadro abaixo da Figura 6, que distingue o Consumo Sustentável do Consumo Verde, assinalando as principais características de ambos.

\begin{tabular}{|c|c|}
\hline CONSUMOVERDE & CONSUMOSUSTENTÁVEL \\
\hline Consumir produtos diferentes & Consumir menos \\
\hline $\begin{array}{l}\text { Essencialmente positivo em relação } \\
\text { ao consumo }\end{array}$ & $\begin{array}{l}\text { Consumo além das necessidades } \\
\text { básicas é negativo }\end{array}$ \\
\hline Mudança no padrão tecnológico & $\begin{array}{l}\text { Mudança no estilo de vida e no } \\
\text { padrão de consumo }\end{array}$ \\
\hline Foco no lado da oferta: produção & Foco na demanda: usuário final \\
\hline $\begin{array}{l}\text { Consumidores respondem às } \\
\text { informações adequadas }\end{array}$ & $\begin{array}{l}\text { Consumidores querem alternativas } \\
\text { de aquisição }\end{array}$ \\
\hline Mudança gradual & $\begin{array}{l}\text { Mudança radical: urgente e } \\
\text { essencial }\end{array}$ \\
\hline $\begin{array}{l}\text { Crescimento verde no lugar de } \\
\text { crescimento econômico }\end{array}$ & $\begin{array}{l}\text { Alta qualidade de vida sem } \\
\text { degradação ambiental }\end{array}$ \\
\hline
\end{tabular}

Figura 6 Abordagens do consumo verde e do sustentável, Fonte: Gonçalvez-Dias e Moura, 2007, p.7.

Consumir de maneira sustentável representa hoje um fenômeno de nicho de mercado, porém deveria ser um modelo de produção e consumo. Sabe-se que, alterações nos padrões de produção e consumo denota um aumento do nível de informação da população, conscientização, eliminação de desperdício, desenvolvimento de novas tecnologias, compartilhar responsabilidades, reciclagem, mas principalmente significa uma mudança do padrão comportamental da sociedade. 


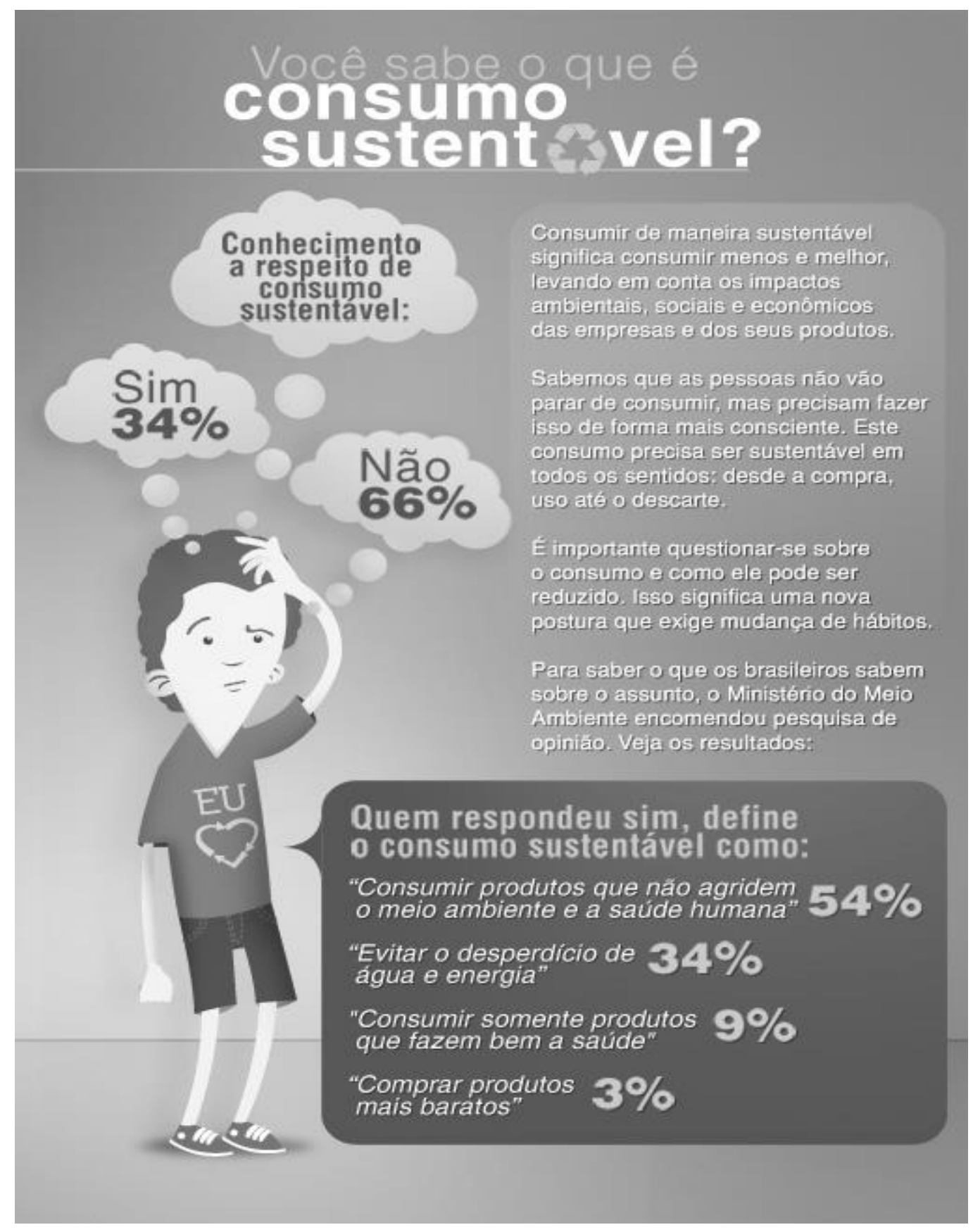

Figura 7 Consumo sustentável, Fonte: Portal Brasil, 2015.

A conscientização sobre o consumo sustentável é extremamente necessária, principalmente quando menos da metade da população não se possui sequer o entendimento do conceito, haja visto os números da pesquisa acima, feita pelo Ministério do Meio Ambiente. 


\subsection{Marketing Verde}

De acordo com Kotler (1996, p. 33), "Marketing é a atividade humana dirigida para a satisfação das necessidades e desejos, através dos processos de troca”. Com essa afirmação, percebe-se que a função do marketing é identificar as necessidades dos consumidores e traçar estratégias para alcançar o público alvo de uma forma que atinja os objetivos desejados.

O autor ainda afirma que o marketing é a estratégia utilizada para chamar a atenção de um determinado mercado consumidor para produtos, serviços, empresas, pessoas, lugares ou causas sociais. Nos dias de hoje, percebe-se uma preocupação em divulgar ideias de conscientização ambiental, sustentabilidade e em favor de causas social, e não apenas um produto, serviço ou empresa.

É devido a essa nova preocupação que surgiu o Marketing Verde, que pode ser determinado como a integração dos objetivos corporativos com a identificação das necessidades do consumidor ao mesmo tempo que se minimiza os danos ecológicos em uma visão de longo prazo (POLONSKI e ROSEMBERG III, 2001). Utilizando a visão clássica do Marketing também se pode definir como um processo de gerenciamento que se responsabiliza por identificar, antecipar e satisfazer as necessidades dos consumidores e da esfera social como um todo, no intuito de tornar-se um negócio lucrativo e ao mesmo tempo sustentável.

O marketing verde, também conhecido como marketing ambiental ou marketing ecológico, é uma modalidade proveniente do marketing que procura atender às necessidades daqueles clientes que possuem um comportamento diferenciado por se preocuparem com medidas sustentáveis e com danos à natureza. Consiste na aplicação da promoção, produção e na recuperação de produtos que são ecológicos e sensíveis ao meio ambiente (BOONE; KURTZ, 2001, p. 71).

Baseado nestes conceitos pode-se relacionar o objetivo do trabalho de acordo com os preceitos do Marketing Verde a medida que a campanha de consumo consciente de água segue estes princípios, tenta de maneira sistêmica avaliar critérios ambientais integrados a elementos de promoção de vendas, utilizando a questão mais fundamental no meio ambiente, que é a água. 


\section{Métodos e procedimentos de coleta e de análise de dados}

\subsection{Etapas de coleta de dados}

A pesquisa foi desenvolvida de forma exploratória bibliográfica primeiramente, para a descoberta de ideias como possíveis oportunidades de aprofundamento e esclarecer circunstâncias ambíguas, que devem ser explicadas para a sequência das próximas etapas.

Posteriormente foi feita uma pesquisa qualitativa no intuito de conhecer o tema mais profundamente, verificar suas propriedades, extrair o significado das respostas obtidas, interpretar os dados para formular significados e assim transformá-los em informação relevante, auxiliando na conclusão necessária para responder à pergunta tema.

Os dados foram coletados por meio de entrevistas, baseadas em um roteiro semiestruturado de perguntas abertas, gravadas e transcritas codificando as respostas, a fim de captar o que era mais relevante na fala dos entrevistados. O roteiro está presente no Anexo do trabalho. A entrevista foi escolhida porque aborda questões específicas e conseguem flexibilizar a interação com o entrevistado para produzir explicações mais profundas e elaboradas sobre o tema. 


\subsection{Perfil dos entrevistados}

Foi utilizado um universo de treze respondentes, para melhor avaliar as respostas observando e interpretando seus dizeres e reações. Este formato se adequa melhor ao caráter exploratório da pesquisa, na tentativa de traçar possíveis explicações para o tema. A escolha dos entrevistados foi feita por conveniência, com amostragem não-probabilística e acessibilidade.

A composição da amostra é pequena e homogênea, formada por oito mulheres e cinco homens. Dentre elas, um respondente entre 18-22 anos, três entre 22-29 anos, duas entre 30-39 anos, duas entre 40-49 anos, quatro entre 50-59 anos e uma com 60 anos ou mais. Logo abaixo segue a tabela com as informações de cada entrevistado.

\begin{tabular}{|c|c|c|c|}
\hline Entrevistados & Sexo & Faixa etária & Profissão \\
\hline 1 & Feminino & $50-59$ & Fisioterapeuta \\
\hline 2 & Feminino & $22-29$ & Engenheira \\
\hline 3 & Feminino & $50-59$ & Pedagoga \\
\hline 4 & Masculino & $60+$ & Médico \\
\hline 5 & Feminino & $40-49$ & Pedagoga \\
\hline 6 & Masculino & $50-59$ & Servidor público \\
\hline 7 & Feminino & $50-59$ & Enfermeira \\
\hline 8 & Masculino & $30-39$ & Advogado \\
\hline 9 & Feminino & $22-29$ & Advogada \\
\hline 10 & Feminino & $18-21$ & Estudante \\
\hline 11 & Masculino & $40-49$ & Administrador \\
\hline 12 & Feminino & $30-39$ & Médica \\
\hline 13 & Masculino & $22-29$ & Estudante \\
\hline
\end{tabular}

Tabela 1 Perfil dos entrevistados 


\subsection{Forma de tratamento e análise de dados}

Os dados serão analisados de forma qualitativa, na qual pretende verificar a relação da realidade com o objeto de estudo, obtendo interpretações necessárias para a descrição do fenômeno estudado.

A pesquisa qualitativa apresenta limitações em relação a falta de estrutura, veracidade das informações, assim como sua precisão, a tornando subjetiva e dependente da interpretação do pesquisador, o que pode ocasionar desvios nas análises. Em relação aos dados secundários é importante verificar a veracidade das fontes para minimizar suposições feitas sobre fatos inverídicos, optando por fontes mais seguras como organizações governamentais e fontes conhecidas de pesquisa. 


\section{Apresentação e análise dos resultados}

Este capítulo apresentará o resultado das entrevistas presentes no Anexo 1 que contemplam vinte e uma perguntas divididas em duas partes. A primeira parte, da pergunta um á treze, traça um sucinto perfil do entrevistado medindo a percepção do problema com a água, característica de seu consumo e referências de empresas ecologicamente conscientes que lhe vem à lembrança. A segunda parte apresenta a campanha Buy A Lady A Drink da Stella Artois, com uma leitura do texto original e exibição de uma imagem promocional, seguindo de mais oito perguntas sobre o conhecimento da mesma e a percepção da marca.

De acordo com as respostas, todos os entrevistados entendem que é necessário o uso consciente da água e que cada um é responsável pelo seu consumo racional, entretanto ocorre muito desperdício. Apesar de ser um recurso necessário para a sobrevivência de todos os seres vivos, há muito o que ser melhorado porque a população não consegue utilizá-la de forma moderada. Como exemplo as respostas abaixo:

"Muitas pessoas ainda usam a água sem se preocupar com a quantidade que se consome, porém é necessário fazer o consumo racional da água, uma vez que é um recurso escasso e essencial para a vida dos seres vivos." (Entrevistado 2)

"Olhando a situação climática e de meio ambiente, a longo prazo penso que será um problema global sério e em alguns lugares já existem muitas pessoas que sofrem de sua escassez." (Entrevistado 7)

“É um bem precioso e precisamos usar de maneira consciente.” (Entrevistado 5)

Considerando o consumo diário de água de 0, gasta-se pouco, a 10, gasta-se muito, notou-se um equilíbrio entre os registros dos entrevistados, o que evidencia um consumo moderado, porém com margem para racionamento. Ou seja, entende-se a importância da economia, mas não se traduz na prática. 
A maioria dos entrevistados acham que o uso desenfreado da água é um problema e tende a se agravar a longo prazo. Percebem que atualmente grande parte das pessoas próximas a eles não sofrem com a sua falta, mas que no futuro certamente sofrerão. Como pode ser verificado nas respostas abaixo:

"Ainda não tomaram consciência da importância da economia da água. " (Entrevistado 1).

"No geral são como eu, sabem que tem que economizar, mas não aplicam de verdade." (Entrevistado 9).

“Muitas pessoas não sabem a importância da água na nossa vida.” (Entrevistado 13).

Dentre as atividades diárias mencionadas pelos respondentes, as que mais consomem água são: tomar banho, lavar louças, lavar roupas, dar descarga, escovar os dentes e lavar o carro. Porém o que mais chamou atenção foi que os entrevistados alegaram um elevado consumo durante o banho. Como consequência, quando foi questionado sobre atitudes para diminuição do volume consumido, e foi citado a redução do tempo de banho como principal fator de racionamento. Como pode ser visto nas respostas abaixo:

"Tomar banho mais rápido, lavar louça fechando a torneira, economizar a água da máquina." (Entrevistado 9)

"Fechar o chuveiro quando estiver me ensaboando ou passando shampoo. Fechar a torneira quando estiver escovando os dentes. Lavar o máximo de roupas possíveis de uma vez só." (Entrevistado 13)

"Diminuir tempo de banho e fechar a torneira enquanto não estiver utilizando, por exemplo: escovando os dentes, lavando louça." (Entrevistado 11)

De forma unanime os entrevistados se consideraram consumidores conscientes dos problemas ambientais do planeta, porém contraditoriamente, somente parte adquirem produtos com algum fator positivo para a natureza, sejam eles: recicláveis, alimentos orgânicos, biodegradáveis ou que consomem menos energia. Utilizando a prerrogativa de causar o menor impacto possível e cuidar melhor da própria saúde. Como exemplo as respostas a seguir: 
"Sim, tento comprar tudo que possível orgânico, eco-friendly², produtos sem impacto ambientais e que não usem animais para teste." (Entrevistado 9)

"Tento causar o menor impacto ambiental possível e cuidar da minha saúde." (Entrevistado 13)

"Não tenho o hábito de analisar o produto antes de comprá-lo. Porém, se o produto informar visivelmente, de modo a chamar a minha atenção, que ele é ecologicamente correto, analiso e compro. "(Entrevistado 2)

Questionados sobre a primeira empresa sustentável que lhes vinham à cabeça, menos da metade souberam citar alguma instituição. Das respostas obtidas mencionaram a Natura, Stella Artois, O Globo e Água Crystal. Quando a questão foi especificamente sobre campanhas de marketing relacionada ao uso consciente de água, mais da metade foi capaz de lembrar. Especificamente recordaram das ações da Stella Artois, Tv Globo e Ambev. Assim o fator economia de água se fez mais presente na memória dos respondentes do que uma marca sustentável especificamente. Como pode ser verificado nas respostas abaixo:

"Sim, campanha da cerveja Stella Artois que leva água potável para as comunidades carentes na África." (Entrevistado 1)

“Sim, a compra da taça da Stella Artois.” (Entrevistado 11)

"Me lembro da Natura, por que ela tem um trabalho muito forte nessa área e tem um ótimo relacionamento com os pequenos fornecedores de matéria prima." (Entrevistado 13)

"Lembro da água AMA, que 100\% do lucro é revertido em benefícios para levar água potável a lugares que não tem acesso." (Entrevistado 2)

2 Eco-friendly: O termo conhecido como amigável ao meio ambiente se refere à produtos, serviços, diretrizes políticas e atitudes que têm o objetivo de causar o menor dano possível à natureza. 
Após a leitura do texto Buy a Lady a Drink e exibir a imagem promocional abaixo seguem as perguntas sobre esta campanha.

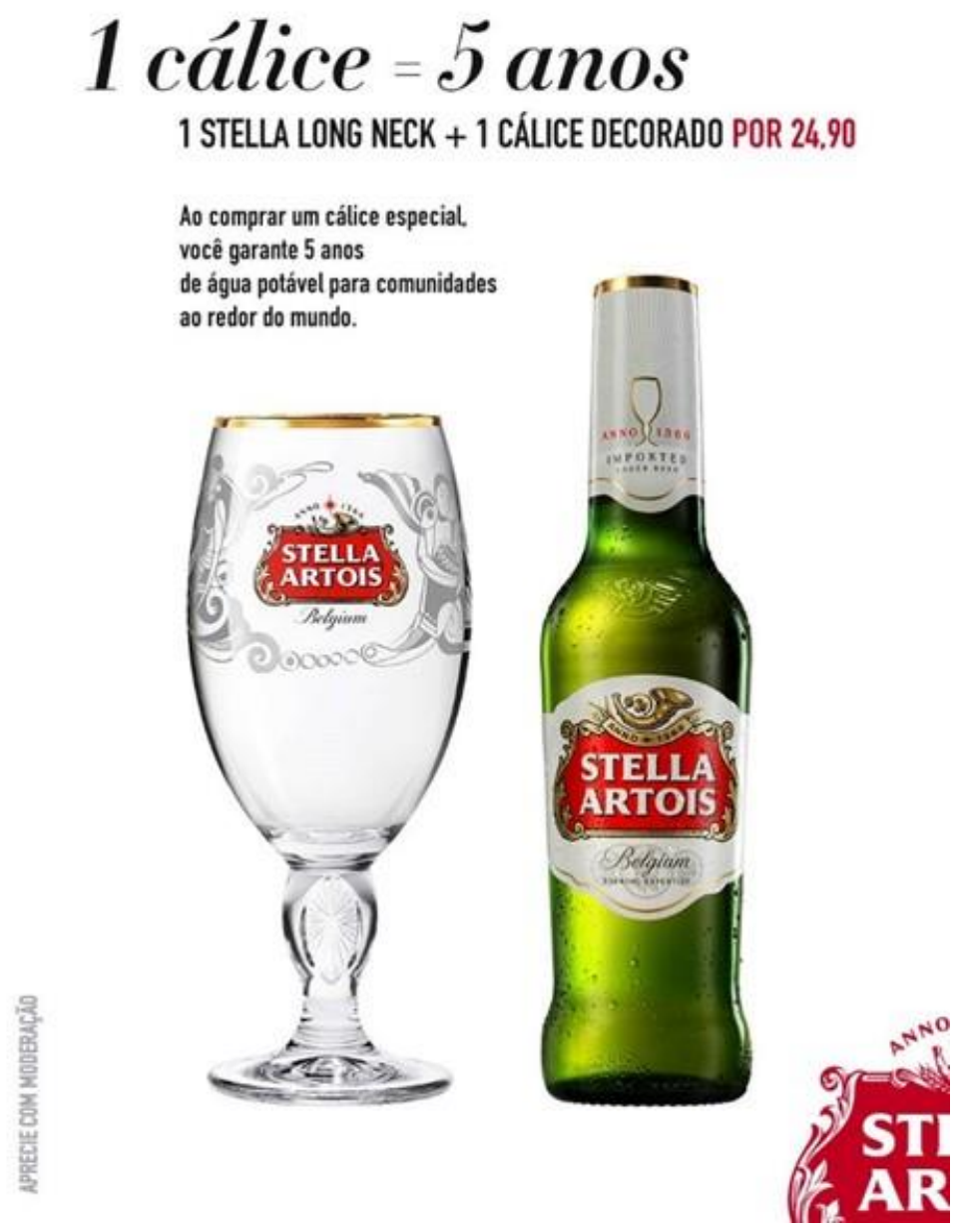

Figura 10 Cálice, Fonte: Stella Artois, 2018.

Mais da metade dos entrevistados não tinha conhecimento da existência desta promoção e quando questionados se sabiam de campanhas parecidas apenas dois citaram a água AMA da Ambev. Como pode ser verificado nas respostas abaixo:

“Lembro da Ambev com a água AMA.” (Entrevistado 2) 
A maioria é formada por não consumidores de cerveja, no entanto todos os conhecedores da campanha consomem o produto, demonstrando que o público alvo da amostra foi atingido com sucesso pela ação de marketing.

A propaganda causou uma impressão positiva da marca, pois todos enxergam a Stella Artois como uma empresa ética e a relacionam como uma companhia que demonstra consciência ambiental, pela sua preocupação em levar auxílio a pessoas necessitadas, garantindo com a compra da taça, água potável por cinco anos a comunidades carentes ao redor do mundo. Como exemplo as respostas abaixo:

“Sim, uma vez que lança uma campanha com o propósito de levar água potável a pessoal que não tem acesso, ela se preocupa com o meio ambiente." (Entrevistado 2)

"Sim, porque se preocupa em atender de forma correta as pessoas que não tem acesso a água e levar essa consciência aos seus consumidores." (Entrevistado 5)

Quando questionados sobre a opinião a respeito da atuação desta empresa na melhoria da qualidade de vida da sociedade, grande parte respondeu que sim, justificando na maioria pelo assistencialismo empregado, contribuindo para a preservação da vida dessas pessoas em condições precárias além de conscientizar seus consumidores a respeito da questão, proporcionando a possibilidade de adquirir o seu produto e ajudar simultaneamente. É válido ressaltar que as opiniões negativas questionaram a veracidade da proposta quanto ao repasse do dinheiro arrecadado, apresentada por dois respondentes. Como pode ser visto nas respostas abaixo:

"Sim, por gastar parte do seu tempo e recursos com parte da população que não tem acesso à água potável." (Entrevistado 6)

"Sim, porquê ela ajuda comunidades carentes que necessitam de água." (Entrevistado 13)

"Sim, porquê ela está contribuindo com a preservação da vida de pessoas sem condições de mantê-las e a preservação do meio ambiente." (Entrevistado 1)

"Sim, porquê tem a intenção de levar um recurso básico a quem não tem acesso." (Entrevistado 2) 
Por fim a percepção dos entrevistados sobre a marca Stella Artois foi solicitada e de forma geral todas as respostas foram positivas, porém segmentadas entre a imagem ambientalmente consciente e a qualidade do produto que oferecem. Como exemplo as respostas abaixo:

"Que é uma marca com consciência ambiental e social, não visando só o lucro, mas está tornando o mundo melhor." (Entrevistado 1)

"Apesar de não ser um consumidor, parece ser uma marca que oferece um produto de boa qualidade." (Entrevistado 2)

"É uma marca que se preocupa com o meio ambiente e que parece atuar de forma consciente e correta, além de levar seus consumidores a agirem de forma a contribuir para que o próximo tenha acesso a água potável e agir de modo ecologicamente melhor." (Entrevistado 5)

"Já admirava a qualidade do produto, mas hoje também reconheço a grandeza da atitude através dessa campanha." (Entrevistado 7)

"Boa cerveja que tem tenta melhor a vida das pessoas." (Entrevistado 13)

“Cerveja muito boa com consciência ambiental.” (Entrevistado 9) 


\section{Conclusões}

Com este trabalho pode-se reforçar a importância da água não só analisando a situação atual, mas também a obrigação moral que o presente possui com as gerações futuras. Diante disto, o trabalho pretendeu investigar a percepção do consumidor em relação ao uso consciente de água, medindo a relevância que é dada estas campanhas, relacionando a imagem das empresas, que possuem esta prática, com comportamento sustentável. Desta forma se adiciona valor a marca, associando a preocupação com o meio ambiente e visão a longo prazo com seus valores.

Aprofundando a análise pretendida, se investigou a perspectiva de Solomon, Michael R. (2011), Kotler e Keller (2006), referente às necessidades, motivações e percepções dos consumidores, assim como sob o aspecto de Polonski e Rosemberg III. (2001), que busca identificar, antecipar e satisfazer as necessidades dos consumidores e da esfera social como um todo, no intuito de tornar-se um negócio lucrativo e ao mesmo tempo sustentável.

Para poder atingir aos objetivos almejados foi realizada a pesquisa exploratória e qualitativa. Foram coletadas treze entrevistas semiestruturadas com uma amostra aleatória não-probabilística. Os dados foram codificados e transcritos para interpretação.

Analisando as entrevistas ficou claro o entendimento do problema e a parcela de participação que cada um possui, porém, a prática do uso consciente ainda não é vista com algo cultural e sua importância não se traduz em comportamento de racionalização, representando uma dissonância cognitiva. Isto pode ser constatado nas análises de consumo diário que cada respondente fez e a solução para o mesmo problema foi uma mudança de atitude. Assim como as considerações feitas sobre ser um consumidor consciente dos problemas ambientais do planeta que não se traduziram na mesma proporção para consumir produtos ecologicamente conscientes, sinalizando o mesmo padrão de comportamento. Entretanto, quando se verificou a percepção efetiva da campanha, os resultados se mostraram positivos a respeito da imagem do anunciante, pois o entendimento foi de que 0 assistencialismo empregado demonstra uma estima tanto pela conscientização do problema da água quanto pela necessidade das comunidades impactadas, despertando o desejo de participar inclusive naqueles que não consomem cerveja. 


\section{Referências Bibliográficas}

AEP - Associação Empresarial de Portugal. Benchmarking Internacional - Práticas de Gestão Sustentável da Água na Indústria. Projeto EFIDRIC - Eficiência Hídrica na Indústria. Junho de 2015. 95 p.

BAISCH, Luciana Beskow; ROCHA, André Lacombe Penna da. Marketing verde e o consumo consciente: um estudo sobre a apelo ecológico de dois produtos. 2008. 115 f. Dissertação (Mestrado em Administração) -Pontifícia Universidade Católica do Rio de Janeiro, Rio de Janeiro, 2008.

BEDANTE, Gabriel Navarro. A influência da consciência ambiental e das atitudes em relação ao consumo sustentável na intenção de compra de produtos ecologicamente embalados. 2004. Tese (Mestrado) - Universidade Federal do Rio Grande do Sul. Escola de Administração. Programa de Pós-Graduação em Administração.

BOONE, L. E.; KURTZ, D. L. Contemporary marketing. Orlando: The Dryden Press, 2001.

GONÇALVES, Ricardo Franci PROGRAMA DE PESQUISA EM SANEAMENTO BÁSICO. Uso racional da água em edificações. Vitória, ES: ABES, c2006. 332 p.

MOREIRA, Leonardo Leal Medeiros. Marketing Verde e Consumo Consciente. 2014. Trabalho de conclusão de curso - Pontifícia Universidade Católica do Rio de Janeiro, Departamento de Administração.

NAVEGA, Thiago Monnerat. O Marketing Verde como vantagem competitiva: Caso Natura. 2010. Trabalho de conclusão de curso - Pontifícia Universidade Católica do Rio de Janeiro, Departamento de Administração.

RICHERS, Raimer. O enigmático mais indispensável consumidor: teoria e prática. Revista da Administração, jul./set. de 1984.

SELBORNE, Lord. UNESCO. A ética do uso da água doce: um levantamento. Brasília, DF: UNESCO Brasil, 2002. 79 p. 
SOLOMON, M. R. O comportamento do Consumidor. 9 ed. Porto Alegre: Bookman, 2011.

VACCARI, Lara Coelho; COHEN, Marcos; ROCHA, Angela Maria Cavalcanti da. O hiato entre atitude e comportamento ecologicamente conscientes: um estudo com consumidores de diferentes gerações. 2014. Tese (Doutorado) -Pontifícia Universidade Católica do Rio de Janeiro, Departamento de Administração.

VERGARA, Sylvia Constant. Projetos e relatórios de pesquisa em administração.2. ed. São Paulo: Atlas, 1998.

ZIKMUND, William G; Babim, Barry J. Princípios de pesquisa de marketing. 2. ed. São Paulo: Cengage Learning, 2011. 508p.

Portal da Folha de São Paulo. Disponível em:

<http://www1.folha.uol.com.br/infograficos/2015/01/118521-agua-no-brasil.shtml> Acesso em 17 de agosto de 2017.

Portal Brasil. Disponível em:

$<$ Http://www.brasil.gov.br/meio-ambiente/2012/10/definicao-do-termo-consumo-conscientee-bem-ampla-informe-se> Acesso em 25 de agosto de 2017.

Portal Brasil Escola. Disponível em:

$<$ https://monografias.brasilescola.uol.com.br/administracao-financas/marketing-comorecurso-para-satisfacao-dos-socios-associacao-cabos-soldados.htm> Acesso em 19 de setembro de 2017.

Portal Globo. Disponível em:

< http://g1.globo.com/economia/crise-da-agua/noticia/2015/03/globo-lanca-campanha-paraincentivar-uso-consciente-de-recursos.html> Acesso em 15 de outubro de 2017.

Portal Planeta Sustentável. Disponível em:

$<$ http://planetasustentavel.abril.com.br/noticia/educacao/agua-nao-cuidar-pode-acabar589849. shtml func $=1 \&$ pag $=2 \&$ fnt $=14 p x>$

Acesso em 15 de outubro de 2017. 
Portal Água AMA. Disponível em:

$<$ https://www.aguaama.com.br/>

Acesso em 19 de setembro de 2017.

Portal Exame. Disponível em:

$<$ http://exame.abril.com.br/negocios/ambev-lanca-sua-primeira-marca-de-agua-mineral-noseua-rio-e-sp/>

Acesso em 19 de setembro de 2017.

Portal ARESPCJ. Disponível em:

<https://http://www.arespcj.com.br/arquivos/59522_Consumo_Sustent\%C3\%A1vel_ARES.pd $f>$

Acesso em 19 de setembro de 2017.

ONU. Relatório Mundial das Nações Unidas sobre Desenvolvimento dos Recursos Hídricos, 2015. 


\section{Anexo 1 Entrevista}

1) Qual é o seu sexo?

2) A qual faixa etária você pertence?

$18-21,22-29,30-39,40-49,50-59$ e $60+$

3) O que você pensa sobre o consumo de água nos dias de hoje?

4) Você acha que isso é um problema?

5) Quais são as atividades diárias que você mais consome água?

6) Você se considera uma pessoa que gasta muita água em seu dia a dia? De 10 (Gasta muita) a 0 (Gasta pouca).

7) O que você acha do comportamento dos seus parentes e vizinhos a respeito?

8) Quais atitudes você pode tomar para ter um menor consumo de água?

9) Você se considera um consumidor consciente dos problemas ambientas do planeta?

10) Você costuma escolher produtos ecologicamente conscientes? Quais?

11) O que te leva a escolher estes produtos?

12) Qual empresa mais ecologicamente consciente que Ihe vem à cabeça? Por quê?

13) Você se lembra de alguma campanha de marketing relacionada ao uso consciente de água? 
Obs: Ler a campanha abaixo, mostrar a imagem e fazer as próximas perguntas relacionadas a ela.

Campanha: Buy A Lady A Drink da Stella Artois.

\section{FAÇA A ÁGUA CHEGAR A QUEM MAIS PRECISA}

Você já imaginou ter que percorrer longas distâncias para fazer atividades básicas como: beber água, escovar os dentes, cozinhar e até tomar banho?

Para milhões de pessoas no mundo em desenvolvimento, essa é a realidade elas gastam muitas vezes até 6 horas por dia para coletá-la. A Stella Artois fez uma parceria com a Water.org para ajudar a mudar isso.

Nosso objetivo é fornecer acesso à água potável a 3,5 milhões de pessoas no mundo em desenvolvimento até 2020. Com o seu apoio, já mudamos a vida de mais de 1 milhão de pessoas desde 2015.

Compre um Cálice Edição Limitada e ajude a levar água potável por até 5 anos a 1 pessoa no mundo em desenvolvimento.

Juntos, podemos fazer a água chegar a quem mais precisa. \#1calice5anos

\section{1 cálice $=5$ anos}

1 STELLA LONG NECK + 1 CÁLICE DECORADO POR 24,90

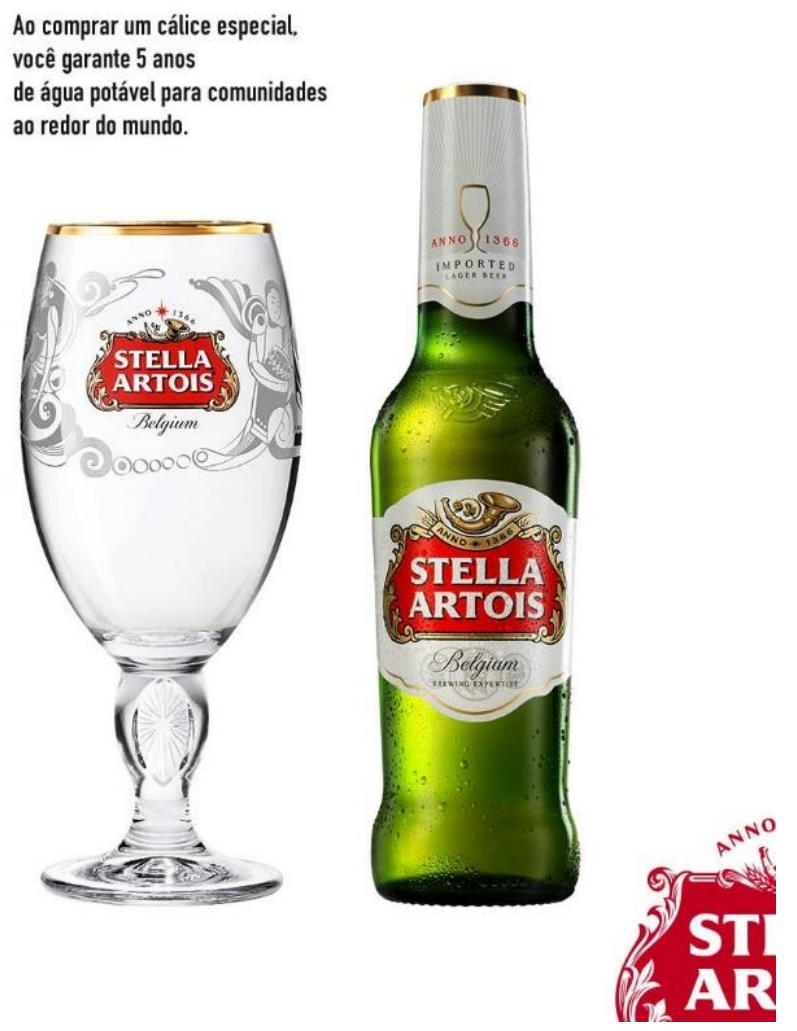


14) Você já conhecia esta campanha?

15) Qual a primeira coisa que lhe vem à cabeça ao vê-la?

16) Você é um consumidor de cerveja?

17) Se lembra de outras marcas com campanhas parecidas?

18) Você acha que esta empresa atua de forma ética?

19) Esta empresa tem consciência ambiental?

20) Você acha que esta empresa atua de forma a melhorar a qualidade de vida da sociedade? Por quê?

21) Qual a percepção que você tem da marca Stella Artois? 